\title{
Review of: "Circulation derived from 4D flow MRI correlates with right ventricular dysfunction in patients with tetralogy of Fallot"
}

hamdy singab

Potential competing interests: The author(s) declared that no potential competing interests exist.

Dear.,

this article need major revision in the following issues:

the manuscript needs English language rediting by specialist medical editor to improve it fluently and flow of its idea.

could you identify what type of circulation (pulmonary or systemic) you referred to in your manuscript . How can MPA geometry affect the MRI circulation index in early postoperative TOF with residual stenosis? Could you identify the exact postoperative time you did your study?

Why all your data does not represented as mean and standard deviation?

What are the baseline demographics of your patients and selection criteria?

what are operative and postoperative criteria of patients of your study 